Methods: The Dutch Arthritis Foundation started its campaign on World Arthritis Day: 'Grow awareness, plant a bulb!'. To 'grow understanding', we created two special tulip bulb fields, one online and one offline, for participants to plant the special 'Anita Witzier' tulip bulb. Anita Witzier is a well-known Dutch television host who suffers from rheumatoid arthritis. She has been ambassador for the Dutch Arthritis Foundation since 2001.

With the help from $70 \%$ of all local RMD patient organisations and a number of garden centres, we handed out a total of 15000 bags of tulip bulbs across the Netherlands. The campaign kick-off was on World Arthritis Day. The event, held on a tulip breeder's field, hosted presentations about incomprehension, and served to share real-life stories.

We also developed a website where people could plant bulbs digitally. Every week, participants receive a video, cartoon, update or article with information about RMDs. The campaign will run until 21 May 2018 when the (real-life) tulips will bloom in our RMD field. All participants can then visit the field to pick a bunch of flowers.

Results: The campaign received a great deal of national media attention on WorldArthritisDay, and featured on television programmes, in newspapers and on online platforms. 8000 people have since signed up for the online tulip field, sharing the information with others in their network. The campaign site drew 68000 visitors between $120 \mathrm{c}$ and $310 \mathrm{c}$ tober. The campaign also resonated with people on Facebook. In October, our campaign posts reached 1,869,000 visitors, with more than 65000 interactions (respond, share, like, watch video, conversion to campaign site).

Conclusions: Raising awareness for incomprehension can be difficult. A creative approach can help to kickstart a public debate. Responses generally show that people with RMDs appreciate this complicated subject being put on the map.

Disclosure of Interest: None declared

DOI: 10.1136/annrheumdis-2018-eular.5271

\section{OP0296 THE RISK OF DELIBERATE SELF-HARM IN RHEUMATOID ARTHRITIS AND ANKYLOSING SPONDYLITIS: A POPULATION-BASED COHORT STUDY}

B Kuriya $^{1,2}$, J. Widdifield ${ }^{3,4}$, J. Luo $^{4}$, S. Vigod ${ }^{4,5}$, N. Haroon ${ }^{1,6}$. ${ }^{1}$ Medicine, University of Toronto; ${ }^{2}$ Rheumatology, Sinai Health System; ${ }^{3}$ Holland Musculoskeletal Research Program, Sunnybrook Research Institute, University of Toronto; ${ }^{4}$ Institute of Clinical Evaluative Sciences; ${ }^{5}$ Psychiatry, University of Toronto; ${ }^{6}$ Rheumatology, University Health Network, Toronto, Canada

Background: Inflammatory arthritis is associated with the development of mental health disorders. However, there is limited data on the risk of serious mental health outcomes following a rheumatoid arthritis (RA) or ankylosing spondylitis (AS) diagnosis.

Objectives: To estimate the risk of deliberate self-harm in patients with ankylosing spondylitis or rheumatoid arthritis compared with the general population. Methods: We evaluated population-based cohorts of RA $(n=53,240)$ and AS $(n=13,964)$, each matched $1: 4$ by age, sex, and calendar year (at diagnosis) with non-IA comparator cohorts in Ontario, Canada. Individuals with a history of mental illness or prior episode of deliberate self-harm were excluded. The outcome was a first emergency room presentation for deliberate self-harm, subsequent to RA or AS diagnosis, between April 1, 2002 and March 31, 2016. We estimated hazard ratios (HR) and 95\% confidence intervals $(95 \% \mathrm{Cl}$ ) for RA and AS, separately, versus the comparator groups, adjusting for demographic, clinical and health service utilisation variables.

Results: Individuals with AS were more likely to deliberately self-harm (incidence rate [IR] of 6.79/10,000 person years [PY] compared to 3.19/10,000 PY in comparators, with an adjusted $\mathrm{HR} 1.82$ (95\% $\mathrm{Cl}: 1.26$ to 2.62). Deliberate self-harm was also increased for individuals with RA (IR 3.51/10,000 PY) compared to comparators (IR 2.45/10,000 PY) only before (HR 1.43, 95\% Cl: 1.16 to 1.75 ), but not after covariate adjustment (HR $1.09,95 \% \mathrm{Cl}: 0.88$ to 1.36). The most frequent method of self-harm was poisoning ( $64 \%$ of attempts in AS, $81 \%$ in RA) or self-mutilation (36\% in AS, $18 \%$ in RA).

Conclusions: There is a significantly increased rate of self-harm attempt in inflammatory arthritis and the risk is particularly elevated following a diagnosis of AS. These findings highlight the need for routine evaluation of self-harm behaviour as part of the management of chronic inflammatory arthritis. Understanding the mechanisms contributing to deliberate self-harm attempts will help tailor preventive strategies to reduce morbidity associated with this serious mental health outcome.

Acknowledgements: This work was funded by the Division of Rheumatology Pfizer Research Chair, University of Toronto

Disclosure of Interest: None declared

DOI: 10.1136/annrheumdis-2018-eular.3004

\section{FRIDAY, 15 JUNE 2018}

\section{More money or more education and collaboration?}

\section{OP0297 DISEASE ACTIVITY IN RHEUMATOID ARTHRITISPATIENTS IS INFLUENCED BY COUNTRIES SOCIOECONOMICS: RESULTS FROM THE METEOR REGISTRY}

S.A. Bergstra ${ }^{1}$, J. Tavares-Costa ${ }^{2}$, M. Garzo-Elizondo ${ }^{3}$, K. Salomon-Escoto ${ }^{4}$ N. Govind ${ }^{5}$, C. Allaart ${ }^{1}$, R. Landewé6. ${ }^{1}$ Rheumatology, LUMC, Leiden, Netherlands; ${ }^{2}$ Unidade Local de Saúde do Alto Minho, Ponte de Lima, Portugal; ${ }^{3}$ Hospital Universitario Dr José Eleuterio Gonzáles, Monterrey, Mexico; ${ }^{4}$ UMass Memorial Medical Center, Worcester, USA; ${ }^{5}$ University of the Witwatersrand, Johannesburg, South Africa; ${ }^{6}$ ARIC, Amsterdam, Netherlands

Background: The treatment and prognosis of rheumatoid arthritis (RA) patients have improved tremendously, but patients across the world may not benefit similarly. One of the potentially critical factors may be poorer access to expensive biologic (b)DMARDs.

Objectives: To investigate daily practice data regarding bDMARD-use in different countries worldwide and assess if a lower country's socioeconomic status (SES) is associated with worse clinical outcomes and lower usage of bDMARDs.

Methods: Data on disease activity and drug use from countries that contributed $\geq 100$ RA patients after 1-1-2000 were extracted from the daily practice, observational METEOR database. Missing data were imputed using multivariate normal imputation (30 cycles). Gross domestic product (GDP) per capita in international dollar (Int|\$) was used as indicator of SES. Per country average DAS28 and the proportion of patients in DA28-remission (DAS28 <2.6) were calculated by taking the average of all patients at the last available visit. Univariable logistic regression analyses were performed to assess associations between GDP, bDMARD use and disease outcomes at a country level.

Results: In total, 20.379 patients were included from 12 countries: United States, Mexico, South-Africa, Japan, Brazil, United Kingdom, Spain, Ireland, Portugal, France, India and the Netherlands. The number of patients ever using a bDMARD varied between $0.9 \%$ (South-Africa) and $75 \%$ (Ireland). The proportion of patients in remission at the final visit varied between $2 \%$ (India) and 39\% (Netherlands). Patients in countries with a higher GDP per capita had a lower average DAS28 and consequently, a higher proportion of them were in DAS28-remission: $\beta$ $(95 \% \mathrm{Cl})-0.32(-0.41 ;-0.021)$ lower DAS28 and an additional $4.2 \%(0.14 ; 8.26)$ of patients in DAS28-remission for every 10.000 Int|\$ additional GDP.

To underscore the assumption that the association between SES and DAS28 is mediated by bDMARD use, we assessed whether SES was associated with bDMARD use per country. Indeed, a higher GDP per capita was associated with a higher proportion of patients using a bDMARD: $\beta(95 \% \mathrm{Cl}) 11.2(4.82 ; 17.5)$, indicating an additional $11 \%$ of patients using a bDMARD per $10.000 \mathrm{Int} \mid \$$ increase in GDP per capita. Furthermore, DAS28 was $\beta(95 \% \mathrm{Cl})-0.14(-0.28 ;-0.0054)$ lower and $2.8 \%(-0.13 ; 5.8)$ more patients achieved DAS28-remission per 10\% increase in proportion of patients using a bDMARD, figure 1 .
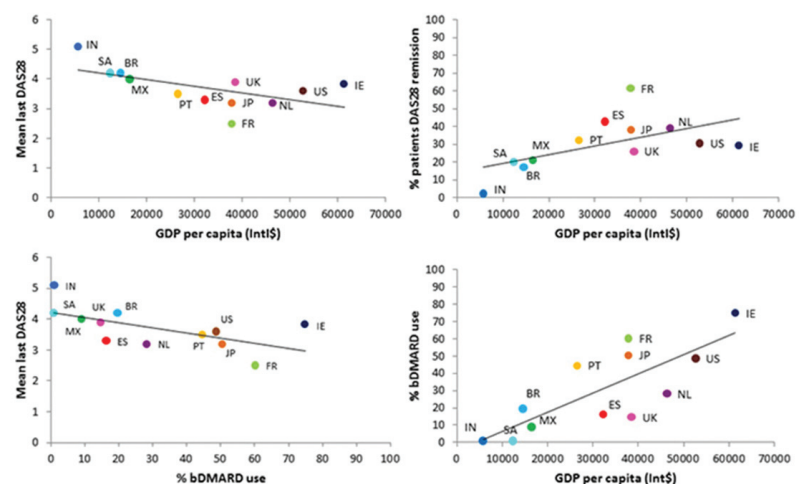

Abstract OP0297 - Table 1 Associated between 'GDP per capita (Int|\$), ‘\% bDMARD use’ and 'disease activity'.

Conclusions: RA patients in countries with a lower SES had worse disease activity. Although patients in countries with a lower SES less often used bDMARDs, the effect of bDMARD use on disease activity was smaller than expected, indicat ing that other factors than access to bDMARDs may contribute to the effectiveness of RA treatment.

Disclosure of Interest: None declared

DOI: 10.1136/annrheumdis-2018-eular.5456 